\title{
Practical Tips
}

\section{Medicare's Hospital Outpatient Prospective Payment System: OPPS 101 (part 2 of 2)}

\author{
By Teri U. Guidi, MBA, FAAMA
}

Oncology Management Consulting Group, Pipersville, PA

Part 1 of this article summarized the origins and structure of the Centers for Medicare and Medicaid Services (CMS) Outpatient Prospective Payment System (OPPS), including which services are reimbursed and at what rates. Here we further elaborate on a number of issues including costs, coding and reimbursement for drugs, facility fees, supervision of therapeutic services, and we briefly discuss the operational issues that can impede optimal financial performance for outpatient infusion services in the hospital setting.

\section{Drugs for Outpatient Infusion}

All providers that administer chemotherapy and the associated supportive drugs must obviously first acquire those drugs. Generally, drugs are acquired through one or more purchasing organizations and involve a complex system of wholesalers and distributors. Hospitals, like physician practices, are often under pressure by payers to use alternative channels (frequently lumped into the category of "brown bagging"). Unlike practices, the majority of community hospitals have resisted this trend, standing on regulatory and licensure requirements and citing the added risks caused by the sheer size and complexity of a hospital system. For example, perishable drugs delivered to a physician office will, theoretically, be readily directed to precisely the right person/location. For a hospital with multiple building addresses, receiving departments, and even pharmacy locations, the risks (again, theoretically, at least) increase. And, as with payer contracting terms, hospitals are larger consumers of products and therefore may have more clout with payers to resist such pressures.

\section{Drug Cost}

Among the most common assumptions we hear from clients is that hospitals get better pricing for drugs than office practices. When an institution is eligible for $340 \mathrm{~B}$ pricing, this is most certainly the case for many (but not all) drugs. The 340B Drug Pricing Program resulted from enactment of Public Law 102585, the Veterans Health Care Act of 1992, which is codified as Section 340B of the Public Health Service Act. Section 340B limits the cost of covered outpatient drugs to certain federal grantees, federally qualified health center look-alikes, and qualified disproportionate-share hospitals. This pricing is intended to mimic the pricing that is available to Veterans Affairs providers, which represents the lowest cost for drugs available to providers in the United States.
As of October 1, 2010, there were 3,650 covered entity sites, ${ }^{1}$ and the Patient Protection and Affordable Care Act of 2010 expands eligibility to a handful of additional entities, creating concern from some physician practices worried that expanded 340B participation will further pressure their practices to move their office-based infusion services to the hospital outpatient department setting. The larger question, however, may be related to the definition and structure of $340 \mathrm{~B}$ eligibility overall. Consider that health care reform seeks to ensure that all individuals carry health insurance. If the number of insured individuals increases, what will be the impact on the number of Medicaid enrollees? And if that number decreases, will many previously 340B-eligible institutions lose that eligibility, or will the formula for eligibility be redefined?

For institutions without access to $340 \mathrm{~B}$ pricing, there is a curious mix in terms of drug acquisition costs. Over-thecounter drugs along with all the basic supplies like gauze, tubing, and so on are generally less expensive to hospitals because they are able to buy in bulk. Prescription drugs, however, are another story. First, there are class-of-trade issues. ${ }^{2}$ In short, although manufacturers are at liberty to set prices for their products, the regulations prohibit manufacturers from offering substantially better pricing for comparable purchases to similar purchasers. Although manufacturer pricing strategy is beyond the scope of this article, this regulation essentially divides provider purchasers into three groups: institutions, practices, and retail pharmacies. A recent client engaged the Oncology Management Consulting Group to determine which class of trade was most beneficial on the basis of their recent purchasing history. The findings indicated that some specific drugs were less costly under the hospital's purchasing contracts, whereas others were less costly under the office practice's contracts. Thus, the mix and volume of specific items purchased will dictate the least costly setting for drug purchasing.

\section{Drug Reimbursement}

As introduced in the first part of this two-part article, CMS reimburses hospitals for drugs differently than it does office-based practices. The major reason for this is that the office-based reimbursement of average sales price (ASP) plus 6\% is a legislated rate, whereas the OPPS rate must retain budget neutrality for CMS (total projected CMS expenditures for all services cannot be increased on the basis of any one or more items without decreasing costs for others) and is set by using a payment-setting methodology 
based on hospital costs (calculated by CMS on the basis of aggregate hospital charges and reported cost-to-charge ratios). With this cost-based methodology, CMS determined that certain drugs carried costs low enough that the reimbursement for drug administration was sufficient to also cover the drug cost. This "packaging" threshold has increased slowly over the years and is set at $\$ 65.00 / \mathrm{d}$ for 2010 and is proposed to be set at $\$ 70.00 / \mathrm{d}$ for 2011 . Thus, drugs that cost less than $\$ 70.00 / \mathrm{d}$ will not paid separately under OPPS.

Each year, to maintain budget neutrality, CMS makes numerous adjustments to the OPPS. Among the most notable is payment for drugs that are not packaged, which fall into two main groups: those with pass-through status and those without pass-through status (pass-through status is granted for only the first 2 to 3 years after a drug becomes payable under OPPS). Pass-through drugs are funded differently than drugs and services that fall under the regular mechanism that requires budget neutrality. Instead, they are paid partly through the regular funding mechanism and partly from other Congressionally allocated sources, allowing budget neutrality to be maintained while also allowing for somewhat higher payments for passthrough drugs. These pass-through drugs are generally paid under OPPS in a manner virtually identical to the rates paid to the private practice (Table 1). Non-pass-through drugs that are not packaged (see above) have been paid at varying rates (ASP since 2005): in 2010, that rate was ASP plus 4\%. For 2011, CMS has increased that rate to ASP plus 5\%.

\section{Facility Fees}

Before the advent of OPPS in 2000, hospitals were permitted to bill what was referred to as a "facility fee" to capture the costs associated with providing space and/or services in the context of other services when those costs would otherwise not be recoverable. With the advent of the OPPS, the rules changed. Hospitals are now permitted to bill what CMS calls a "visit" under certain circumstances for outpatient services. The codes used for these services borrow from the Current Procedural Terminology (CPT) code set, and CMS expects that under most circumstances, the hospital will use the established patient codes (992xx). There has been much confusion and concern among hospital compliance officers and legal counsel because the CPT definition of those codes does not match CMS's definition. Still, there is abundant guidance from CMS on this topic. ${ }^{3}$ The end result is that hospitals may bill for the facility component of the costs to provide care if that service is separate and distinct from any other billable procedure/service delivered at the same encounter. This will be extremely rare when the encounter includes chemotherapy. However, if a physician (employed or not) has a patient encounter such as an Evaluation and Management service using space and resources not captured in the billed professional service (eg, when the professional service is billed at place of service 22, indicating that the physician does not bear the overhead associated with the encounter), then the hospital may be entitled to bill for the facilityrelated expenses such as space, supplies, and staff associated with the physician encounter (Table 2). Clearly, the limitations on
Table 1. Drugs Proposed for 2011 Pass-Through Status

\begin{tabular}{|c|c|}
\hline $\begin{array}{l}\text { CY } 2010 \\
\text { HCPCS Code }\end{array}$ & CY 2010 Long Descriptor \\
\hline A9582 & $\begin{array}{l}\text { lodine } \mathrm{i}-123 \text { iobenguane, diagnostic, per study dose, up } \\
\text { to } 15 \text { millicuries }\end{array}$ \\
\hline A9583 & Injection, gadofosveset trisodium, $1 \mathrm{~mL}$ \\
\hline C9250 & $\begin{array}{l}\text { Human plasma fibrin sealant, vapor-heated, solvent- } \\
\text { detergent (Artiss), } 2 \mathrm{~mL}\end{array}$ \\
\hline C9255 & Injection, paliperidone palmitate, $1 \mathrm{mg}$ \\
\hline C9256 & Injection, dexamethasone intravitreal implant, $0.1 \mathrm{mg}$ \\
\hline C9258 & Injection, telavancin, $10 \mathrm{mg}$ \\
\hline C9259 & Injection, pralatrexate, $1 \mathrm{mg}$ \\
\hline C9260 & Injection, ofatumumab, $10 \mathrm{mg}$ \\
\hline C9261 & Injection, ustekinumab, $1 \mathrm{mg}$ \\
\hline C9262 & Fludarabine phosphate, oral, $1 \mathrm{mg}$ \\
\hline C9263 & Injection, ecallantide, $1 \mathrm{mg}$ \\
\hline C9264 & Injection, tocilizumab, 1 mg \\
\hline C9265 & Injection, romidepsin, $1 \mathrm{mg}$ \\
\hline C9266 & Injection, collagenase Clostridium histolyticum, $0.1 \mathrm{mg}$ \\
\hline C9267 & $\begin{array}{l}\text { Injection, von Willebrand factor complex (human), wilate, } \\
\text { per } 100 \text { U vwf:fco }\end{array}$ \\
\hline C9268 & Capsaicin, patch, $10 \mathrm{~cm}^{2}$ \\
\hline C9360 & $\begin{array}{l}\text { Dermal substitute, native, nondenatured collagen, } \\
\text { neonatal bovine origin }\end{array}$ \\
\hline C9361 & $\begin{array}{l}\text { Collagen matrix nerve wrap (neuromend collagen nerve } \\
\text { wrap), per } 0.5 \mathrm{~cm}\end{array}$ \\
\hline C9362 & $\begin{array}{l}\text { Porous purified collagen matrix bone void filler (Integra } \\
\text { Mozaik) }\end{array}$ \\
\hline C9363 & $\begin{array}{l}\text { Skin substitute, integra meshed bilayer wound matrix, } \\
\text { per square centimeter }\end{array}$ \\
\hline C9367 & $\begin{array}{l}\text { Skin substitute, endoform dermal template, per square } \\
\text { centimeter }\end{array}$ \\
\hline J0598 & Injection, c1 esterase inhibitor (human), $10 \mathrm{U}$ \\
\hline J0641 & Injection, levoleucovorin calcium, $0.5 \mathrm{mg}$ \\
\hline J0718 & Injection, certolizumab pegol, 1 mg \\
\hline J1680 & Injection, human fibrinogen concentrate, $100 \mathrm{mg}$ \\
\hline J2562 & Injection, plerixafor, 1 mg \\
\hline J8705 & Topotecan, oral, 0.25 mg \\
\hline J9155 & Injection, degarelix, 1 mg \\
\hline J9328 & Injection, temozolomide, $1 \mathrm{mg}$ \\
\hline Q0138 & $\begin{array}{l}\text { Injection, ferumoxytol, for treatment of iron deficiency } \\
\text { anemia, } 1 \mathrm{mg} \text { (non-ESRD) }\end{array}$ \\
\hline Q2025 & Fludarabine phosphate, oral, $1 \mathrm{mg}$ \\
\hline
\end{tabular}

Abbreviations: CY, calendar year; HCPCS, Healthcare Common Procedure Coding System; ESRD, end-stage renal disease.

Table 2. 2011 OPPS Payment

\begin{tabular}{ll}
\hline HCPCS Code & 2011 OPPS National Payment \\
\hline 99211 & 52.36 \\
99212 & 75.13 \\
99213 & 75.13 \\
99214 & 99.71 \\
99215 & 128.48 \\
\hline
\end{tabular}

Abbreviations: HCPCS, Healthcare Common Procedure Coding System; OPPS, Outpatient Prospective Payment System. 
when a hospital can bill for these visits (aka facility fees) significantly reduce the likelihood that these visits will generate significant revenue.

\section{Physician Supervision}

For 2011, CMS made many clarifications regarding requirements for physician supervision for outpatient therapeutic services. The requirements address two scenarios: (1) the hospital outpatient department is deemed to be physically part of the main provider, and (2) the hospital outpatient department is deemed to be provider based but off the campus of the main provider. The details regarding these two scenarios are quite complex, but in general, if the hospital's infusion suite is physically connected to or on the campus of the main hospital, the first category applies. If the suite is off campus but qualifies as a hospital outpatient department, then the second category applies. There are also certain exceptions for some hospitals such as rural health clinics and sole community hospitals, but for most, the following applies.

For both categories, the following is clarification from $\mathrm{CMS}^{4}$ :

... nonphysician practitioners, specifically physician assistants, nurse practitioners, clinical nurse specialists, and certified nursemidwives, may directly supervise all hospital outpatient therapeutic services that they may perform themselves in accordance with their state law and scope of practice and hospital-granted privileges, provided that they continue to meet all additional requirements, including any collaboration or supervision requirements as specified in the regulations...

For outpatient services furnished by a hospital

... we are revising our definition of direct supervision for hospital outpatient therapeutic services in $\$$ 410.27(a)(1) (iv)(A) and (B) to remove the reference to "on the same campus" or "in the off-campus provider based department of the hospital" and we are removing our definition of "in the hospital or CAH” provided under $\$ 410.27(\mathrm{~g})$ entirely. The definition of direct supervision will be revised simply to require immediate availability, meaning physically present, interruptible, and able to furnish assistance and direction throughout the performance of the procedure but without reference to any particular physical boundary. [... .] We wish to give CAHs and other hospitals more flexibility to meet the direct supervision requirement by allowing physicians or other practitioners in locations that are close to the hospital but not in actual hospital space to directly supervise services that are within their State scope of practice and hospital granted privileges, so long as these individuals remain immediately available. This policy also allows supervision from any location within a building off-campus that houses multiple PBDs of a hospital as long as the supervising practitioner is immediately available, rather than requiring a supervising practitioner to be located within each PBD in that building. We note, however, that we are not relaxing the requirement that, for direct supervision, the supervisory physician or nonphysician practitioner must be immediately available, meaning that the supervisory practitioner must be physically present and interruptible. We wish to emphasize that once we remove reference to "in the hospital" or "in the provider based department," we continue to expect the supervisory practitioner to be physically present for the services he or she is supervising. As in the past, we are not defining immediate availability in terms of time or distance. We believe that removing specific boundaries provides reasonable flexibility but also holds the practitioner accountable for determining, in individual circumstances, how to be physically and immediately available when supervising services provided "incident to a physician's service in the outpatient setting."

For on-campus hospital outpatient infusion departments, a supervising nonphysician practitioner may be an employee or a contracted provider of the hospital. As a result of the requirements to qualify as a provider-based department of the hospital, for offcampus "provider based" outpatient infusion suites, the supervising nonphysician practitioner must be an employee of the hospital.

\section{Summary}

There are many obvious differences for billing and reimbursement for outpatient oncology services in the hospital outpatient department versus in the office-based setting. The details can be difficult for hospitals to master because outpatient oncology is just one of many service lines to be billed. And the coding, billing, and payment details represent only part of the challenge for hospitals. Institutions are large and complex organisms, with many departments handling components of the entire continuum of delivering and billing for services. This often leads to significant fragmentation or miscommunication. For example, if the department responsible for maintaining the system to record charges (the charge master) is not well informed regarding changes in coding and billing requirements, important codes or code definitions may not be current and accurate, making it impossible for charge entry staff to choose the correct items. Or if the department responsible for patient registration is not aware of payer nuances regarding the use of specific drugs for certain diagnoses, they will not know that a predetermination of insurance coverage is needed. Finally, the pharmacy charge entry system may record the units of drug dispensed, but if those units do not match the Healthcare Common Procedure Coding System unit definition of billable dose, then drug charges can be grossly under- or overstated. Thus, hospitals frequently find it extremely difficult to match the detailed expertise that most office-based practices have developed through years of specialty focus.

\section{Accepted for publication on November 17, 2010.}

\section{Author's Disclosure of Potential Conflicts of Interest}

The author indicated no potential conflicts of interest.

Corresponding author: Teri U. Guidi, MBA, FAAMA, 241 Smithtown Rd, Pipersville, PA 18947; e-mail: tguidi@oncologymgmt.com. 


\section{References}

1. US Department of Health and Human Services, Health Resources and Services Administration, Office of Pharmacy Affairs: Daily Reports. http://opanet. hrsa.gov/opa/Report/DailyReport.aspx

2. Anti-Price Discrimination Act, Pub. L. No. 74-692, 49 Stat. 1526, 15 U.SC $\S 13$

3. US Department of Health and Human Services, Center for Medicare and
Medicaid Services: Claims Processing Manual (chapter 4, section 160).http:// www.cms.gov/Manuals//OM/list.asp

4. Federal Register November 20, 2009: 42 CFR Parts 410, 416, and 419 Medicare Program: Changes to the Hospital Outpatient Prospective Payment System and CY 2010 Payment Rates; Changes to the Ambulatory Surgical Center Payment System and CY 2010 Payment Rates; Final Rule

\section{Cancer.Net ${ }^{\mathrm{TM}}$}

Cancer.Net brings the expertise and resources of ASCO, the voice of the world's cancer physicians, to people living with cancer and those who care for and about them. All the information and content on Cancer.Net is developed and approved by the experts at ASCO, making Cancer.Net the most up-to-date and trusted resource for cancer information on the Internet. Cancer.Net is made possible by The ASCO Cancer Foundation $\AA$, which provides support for cutting-edge cancer research, education, and 